\title{
The Importance of Being Standard
}

Anna Gelpern

Georgetown University Law Center, ag1348@law.georgetown.edu

This paper can be downloaded free of charge from:

https://scholarship.law.georgetown.edu/facpub/1971

https://ssrn.com/abstract=2963333

European Central Bank 2016 Annual Legal Department Conference Proceedings (January 2017)

This open-access article is brought to you by the Georgetown Law Library. Posted with permission of the author. Follow this and additional works at: https://scholarship.law.georgetown.edu/facpub

Part of the Banking and Finance Law Commons, and the Contracts Commons 


\section{The importance of being standard}

Published at https://www.ecb.europa.eu/pub/pdf/other/escblegalconference2016_201702.en.pdf Posted with permission

\section{By Anna Gelpern ${ }^{1}$}

Contract standardisation serves many important functions in the sovereign debt market: among these, it saves time and money in preparing documents and endows widely-used terms with a shared public meaning, which in turn saves investors the costs of acquiring information, facilitates secondary market trading and reduces the scope for mistakes in the judicial interpretation of contract terms. Sovereign debt issuers and investors claim to value standardisation and list it as an important contractual objective. Issuers generally insist that their bond contracts are standard and reflect market practice. Variations from past practice and market norm must be explained in disclosure documents and through market outreach. Standardisation is not just part of the fabric of market expectations: international policy initiatives to prevent and manage financial crises rest on the assumption that sovereign debt contracts follow a generally accepted standard. Such initiatives would make no sense in the absence of standardisation.

In fact, sovereign bond contracts are not nearly as standardised as market participants and policy makers seem to suggest. It is common to see a handful of negotiated terms embedded in a mish-mash of different generation industry models, sprinkled with bits of creative expression that no one can explain, usually attributed to some long-forgotten lawyers. At least some of the variation appears to be deliberate. However, to the extent that it is inadvertent, variation can be costly. For example, it can make contracts internally inconsistent, vulnerable to opportunistic lawsuits and errors of judicial interpretation. Variation could also make debt instruments less liquid, especially during periods of market stress.

The problem of inadvertent variation would diminish substantially if sovereign debt markets were to adopt a more centralised, modular approach to contracting, whereby a subset of widely-used non-financial terms would be produced by an authoritative third party (a public, private, or public-private body) and incorporated by reference in individual transactions. Debtors and creditors would have to add party- and transaction-specific terms, and could still depart from centrally-produced default terms. However, any variation would be in a separate document, which would make it salient and thus easier to detect and evaluate than under the prevailing contract production regime. Market participants and the courts could rest assured that the terms purporting to be standard were in fact standard and that any departures from the standard were intentional and meaningful. Centralised production of standard terms would maximise the advantages of standardisation, amplify the signalling capacity of bespoke terms, facilitate the diffusion of optimal contract innovations across the sovereign debt market and reduce the legacy stock problem that has

1 Professor, Georgetown Law and non-resident senior fellow at the Peter G. Peterson Institute for International Economics. I am grateful to the participants in the conference at the ECB and the University of Virginia Law School, and to Mitu Gulati, Angel Ubide, and Pierre Verdier for insights that contributed to this essay, and to Sebastian Röing for research assistance. 
stumped policy makers and market participants ${ }^{2}$. Terms that have lost relevance through boilerplate iteration over time would be revised or culled more readily than they are today. ${ }^{3}$

Centralised and modular contracting is not new in finance. Versions of the practice just described, where an industry group supplies core terms for contracts spanning an entire market, exist in foreign exchange and derivatives markets, as well as in trade finance. ${ }^{4}$ More distant analogues, where certain default terms are supplied by statute or treaty, are also common, especially in civil law systems. ${ }^{5}$ The Uniform Commercial Code, adopted by US states, and the UN Convention on Contracts for the International Sale of Goods are among the examples from common-law jurisdictions. Most industry and statutory models of standardisation share three key features: central production of some terms, modularity (enabling combinations of customised and standard terms, selected from a menu) ${ }^{6}$ and a commitment to revision.

In many ways, sovereign bonds are ideal candidates for centrally produced modular contracts. They tend to be actively traded, serve as price benchmarks for other borrowers and as collateral for other financial products, and are often favoured by regulated financial firms. Minimising information and transaction costs and errors of interpretation is especially important in such a market.

The transition would not require a radical departure from current contracting practice. Sovereign debt contracting already has elements of modularity and centralisation. For instance, non-financial terms of domestic government debt are typically found in regulations; financial terms are announced at transaction time. External government debt commonly follows the practice of issuing multiple series of bonds with different financial terms pursuant to a single indenture or fiscal agency agreement, for example, under medium-term note (MTN) programmes and "shelf" registration filings with securities regulators. government debt management fora, financial industry associations and ad hoc groups of senior policy officials already issue non-binding guidance on sovereign debt contracts, invest in diffusing this guidance and coordinate ongoing reforms.

For all these reasons, sovereign debt markets could plausibly achieve a higher degree of standardisation by switching to robustly centralised, modular contract production. Such reform would bring new political economy challenges. Sovereigns,

2 International Monetary Fund (IMF), Progress Report on Inclusion of Enhanced Contractual Provisions in International Sovereign Bond Contracts (September 2015), available at:

http://www.imf.org/external/np/pp/eng/2015/091715.pdf, pp. 9-10.

3 Stephen J. Choi, G. Mitu Gulati and Robert E. Scott, The Black Hole Problem in Commercial Boilerplate (November 25, 2016), Working Paper, available at: www.ssrn.com/abstract=2835681

4 Boilerplate as a public good, and the case for contract production by trade groups and other nonprofits, are analysed in Kevin E. Davis, The Role of Nonprofits in the Production of Boilerplate, 104 Michigan Law Review 1075 (2006).

5 See, for example, Claire A. Hill and Christopher King, How Do German Contracts Do as Much with Fewer Words?, 79 Chicago-Kent Law Review 889 (2004).

6 An extensive theoretical treatment of modularity in standard-form contracts is found in in Henry E. Smith, Modularity in Contracts: Boilerplate and Information Flow, 104 University of Michigan Law Review 1175 (2006) 
along with their public and private creditors, would have to agree on a body to draft and periodically update standard terms, coordinate their adoption, maybe even to issue authoritative interpretations. Sovereign governments, foreign and domestic creditors, civil society and international institutions would all have a stake in the outcome of this body's work. If the centrally produced terms were to function as a strong default, their political salience would be high, raising barriers to coordination. Since sovereign debt markets are hierarchical and segmented both among issuers and investors, status and representation concerns would loom large. Finally, there would certainly be constituencies against change in any form, including lawyers and bankers in New York and London, who may have to give up influence and at least a portion of their fees, as well as those issuers and investors who would prefer to drown their idiosyncratic terms and arbitrage opportunities in the noise of apparently unintentional variation.

Despite these caveats, moving to more robust standardisation makes sense for the foreign sovereign debt market, if not for sovereign debt in general. The remainder of this essay elaborates the argument. Part I defines standardisation and considers its benefits and costs in financial contracts. Part II discusses sovereign debt contract production, reform initiatives and the controversy over variation in the pari passu clause, which featured in recent sovereign debt litigation. Part III touches on statutory and judicial solutions to the problem of incomplete standardisation and elaborates an alternative solution, featuring centralised production of terms. Part IV outlines what centralised and modular contracts might look like in foreign sovereign debt and raises possible objections to such a contracting regime. I conclude by identifying the implications for research and policy.

Classic law texts on contract standardisation treat standard ("boilerplate") terms as if they were identical within the standard: at the extreme, comprising the same words in the same order, with the same punctuation. ${ }^{7}$ If the assumption is essentially correct, then even small variations in language must be presumed to be intentional and treated as meaningful by the parties and the courts. ${ }^{8}$ On the other hand, if the concept of "standard" allows some scope for variation without necessarily altering the effect of the contract term - perhaps as a matter of individual or firm drafting style, or local idiomatic usage - then the parties and the courts would have to first

8 See, for example, the following papers: Marcel Kahan and Shmuel Leshem, "Moral Hazard and Sovereign Debt: The Role of Contractual Ambiguity and Asymmetric Information," Working Paper (29 February 2016) available at: www.law.uchicago.edu/files/file/moral_hazard_and_sovereign_debt.pdf and Mark C. Weidemaier and Mitu Gulati, A People's History of Collective Action Clauses, $\overline{5} 4$ Virginia Journal of International Law 1 (2014). 
decide whether the words before them mean to convey a distinct meaning or merely express the same thing differently.

Standard contracts, like standard terms, can also range from identical to broadly similar, or "of the same type." For example, a standard consumer loan agreement might be entirely pre-printed, with only a few blanks to be completed at the closing by a bank clerk. A standard sovereign or corporate bond might contain a customary set of terms arranged in the usual order; however, not all terms are found in all bond contracts, some terms might come in several distinct yet standard "flavours," while other term types might permit a measure of variation within an accepted range. Thus two bonds might contain very different negative pledge clauses, yet both clauses would be considered standard - provided the standard comprises several alternatives, or permits variation - and, as a consequence, the bonds would be considered standard as well.

Some terms or variations are found only in bonds of a particular credit quality, or in a certain geographic region. The resulting contract is standard for its type, for example, an emerging market sovereign bond issued in London, or a Latin American corporate bond issued in New York.

Investors might take a checklist approach to contract analysis, asking simply whether a term type is present in the contract: is there a negative pledge clause? ${ }^{9}$ They might also ask whether the term itself is "standard," meaning whether it follows one of the accepted conventions for the relevant market. If enough of the customary terms are present and standard, the contract would be treated as standard. Only rarely would the investor parse the wording of a term to assess whether it departs from the standard and thus represents a risk or an arbitrage opportunity.

\section{$1.2 \quad$ Benefits}

Standard-form contracts are ubiquitous; their advantages in lowering transaction costs and conveying information are well-rehearsed. ${ }^{10}$ These advantages are especially pronounced in financial contracts among sophisticated parties. This subsection provides a very brief summary.

Standardised contracts are quicker and easier to produce. Reproducing and customising standard forms saves research, drafting and negotiation costs over generating text from scratch. Contract counterparties may pay less to service providers and middlemen, such as lawyers and investment bankers arranging the transaction. Even if it did not produce cost savings overall, standardisation can help deploy the resources allocated to contract production more efficiently. This is because the time and energy that might have been spent drafting and analysing

9 For example, Bloomberg offers a bond-level covenant checklist as part of its fixed-income portfolio management toolkit. If a bond contains one of the listed covenants, the word "Yes" appears opposite the covenant name. The screen contains no further information on the nature and content of the covenant, which only makes sense if all covenants that go by the same name have the same substantive effect.

10 See, for example, Klausner and Kahan, supra footnote 7, for a good overview. 
frequently-used terms can now be devoted to novel and transaction-specific challenges. As an additional benefit, compressing the transaction preparation period allows issuers and investors to take advantage of time-sensitive market opportunities.

Widespread, repeated use imbues standard terms with a meaning shared among the relevant market participants. This has multiple important implications for financial contracts. Shared meaning reduces the cost of information acquisition in secondary market trading. Buyers and sellers who know that a bond contract is standard do not need to research its meaning before deciding whether to trade it. Conversely, variation becomes more salient against a background of standard terms. The combination of a strong standard and deliberate, easily discernible variation in contract terms makes it easier to convey information - for example, to signal willingness or ability to repay.

Standard terms with shared meaning can become important tools in coordinating market-wide response to shocks and other contingencies. Contracts can effectively codify market practices and spur the development of institutional infrastructure, for example, to guide the parties through early termination and substitute performance, procedures for interest rate and exchange rate calculation, as well as notice, payment and settlement mechanics. If a dispute over the meaning of a standard term goes to court, the existence of a shared meaning can save adjudication costs and help avoid interpretation error. Judges can (and generally must) presume that the parties used standard terms in standard ways, which are easier to access than the parties' idiosyncratic, subjective meanings. ${ }^{11}$

\subsection{Costs}

The downsides of standardisation, like its advantages, are related to its coordination properties. For example, if all contracts provide for the same response to counterparty financial distress, or to drastic exchange rate depreciation, standardform contracts can amplify financial contagion: all market participants might rush to sell at the same time. ${ }^{12}$ Furthermore, standardisation can raise the cost of individual judicial errors even if it were to reduce the overall incidence of such errors. When a standard term is misunderstood and misapplied by a court, the immediate effect is market-wide, potentially triggering a different form of contagion.

The risk of judicial misconstruction is particularly high when old boilerplate terms remain in standard-form contracts despite losing all or most of their practical relevance. Such contractual "black holes" ${ }^{13}$ are ripe for exploitation by enterprising litigators, who can convince a court to fill them with new meaning and potentially

11 For an influential framing of judicial treatment of standard and customised terms, see Charles J. Goetz and Robert E. Scott, The Limits of Expanded Choice: An Analysis of the Interactions between Express and Implied Contract Terms, 73 California Law Review 261 (1985).

12 See, for example, Erik F. Gerding, Contract as Pattern Language, 88 Washington Law Review 1323 (2013).

13 Choi, Gulati and Scott, supra footnote 3. 
trigger a market shock. On the other hand, standard terms can become selfperpetuating and impede the very sort of innovation that might avoid or correct judicial mistakes, or improve procedures to deal with crises.

A host of collective action problems may stand in the way of changing standard terms for the better. A new term might be costly to design but easy to replicate, dissuading potential first movers from investing resources they would find hard to recoup. Debtors may resist deviating from the standard for fear of sending a negative signal to the market. ${ }^{14} \mathrm{~A}$ novel term, even one designed to correct an earlier judicial misunderstanding, can be misconstrued by a court; in any event, its meaning may not be settled for some time. ${ }^{15}$ A contract containing the new term may be less liquid for as long as traders are unsure of its meaning, or how it fits into the institutional ecosystem that developed around the old boilerplate. Debtors and creditors may also delegate the task of updating their standard-form contracts to outside law firms, which come with their own organisational barriers to innovation. ${ }^{16}$

In sum, contract standardisation has many benefits, but also comes with costs, including a tendency to amplify contagion from interpretive and other shocks and to stunt optimal innovation. I consider these benefits and costs in the context of foreign sovereign bonds in Part II. Part of the challenge with these bonds is the apparent lack of consensus on the sort of standardisation that should prevail in any given case - identical words/identical effect, or different words/identical effect - and whether sovereign debtors, their creditors, their citizens and other stakeholders in fact understand and intend the type of standardisation they are getting.

\section{Contract form and contract production}

At the highest level of generality, there are two kinds of sovereign bond contracts: domestic and foreign. Most sovereign debt belongs in the former category; it is issued under the debtors' own law and in their domestic markets. Domestic sovereign bond terms vary considerably across countries, reflecting local legal and market idiosyncrasies. Within each sovereign's domestic debt stock, non-financial terms tend to be consistent: they are not negotiated from issue to issue, but are typically published in government regulations. Foreign sovereign debt - here, debt issued under foreign law, usually outside the borrower's jurisdiction - tends to adopt

14 Why change the negative pledge clause unless you plan to pledge? Why provide for a restructuring process if you do not plan to restructure?

15 See, for example, Goetz and Scott, supra footnote 11.

16 See, for example, Mitu Gulati and Robert E. Scott, The Three and a Half Minute Transaction Boilerplate and the Limits of Contract Design, University of Chicago Press, 2013; Barak D. Richman, Contracts Meet Henry Ford, 40 Hofstra Law Review, 77 (2011). 
the contracting customs of its chosen law market. ${ }^{17}$ New York and English law dominate this category and are the focus for the remainder of this essay; however, German, Japanese and Swiss law contracts, among others, have been important for some sovereigns.

New York and English law sovereign debt securities are issued under a contract that describes the relationship between the debtor and the securities holders, including the holders' rights vis-à-vis one another and the sovereign. This contract - a trust indenture (New York), a trust deed (London), or a fiscal agency agreement contains the core non-financial debt terms and may append a form of the security or securities to be issued. It has become common for sovereign borrowers to issue multiple series of securities under a single trust document or fiscal agency agreement, which contemplates a range of financial terms to be spelled out in future supplemental agreements. Figure 1 illustrates:

\section{Figure 1}

Sovereign bond contract architecture

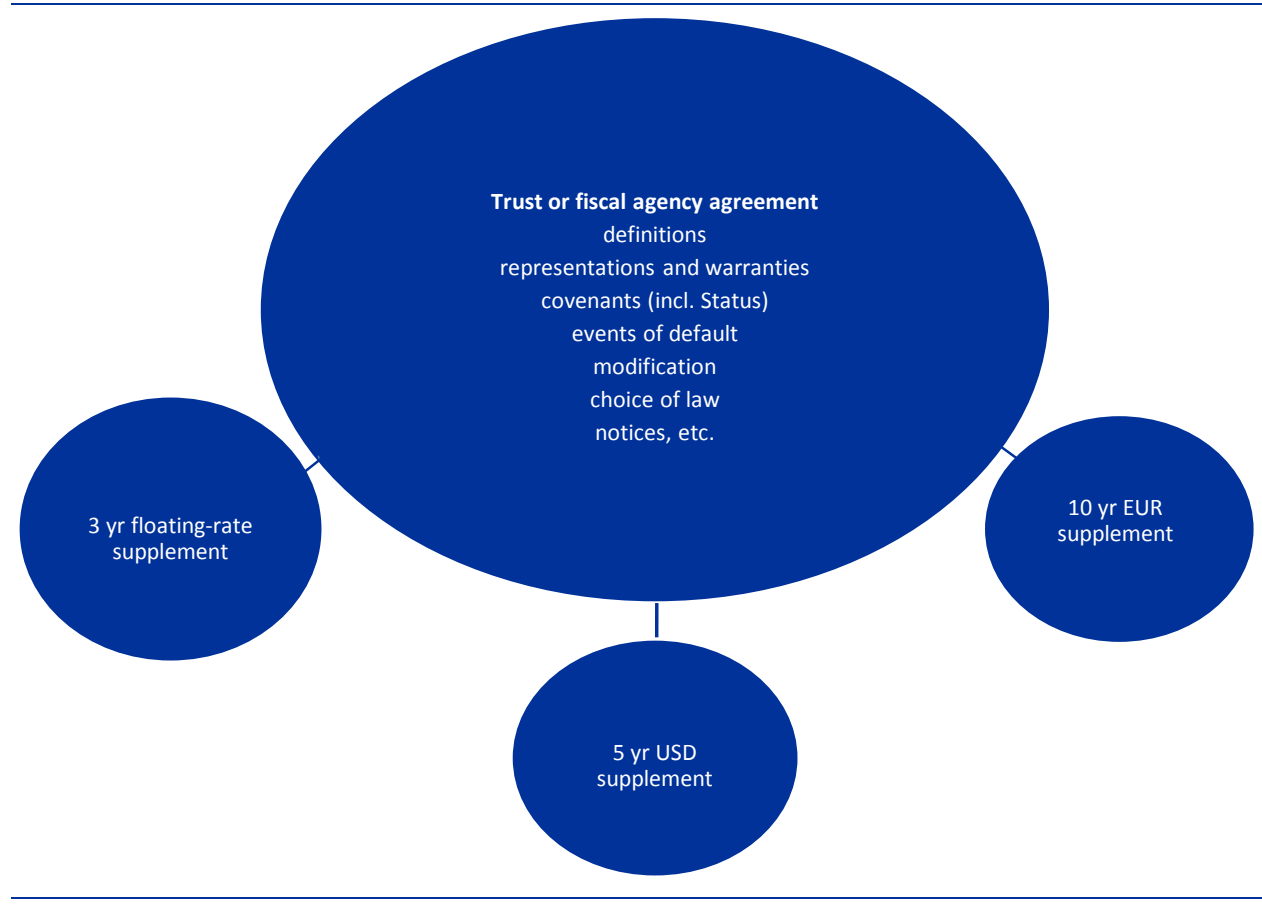

There is a modular, hub-and-spokes quality to this contract. Non-financial terms, which range from ministerial to substantively significant (notably including waiver of immunity, governing law, status, payment, events of default and modification procedures) are agreed with the sovereign's investment bankers and produced by outside counsel, all paid by the issuer. Although parts of the negotiation and drafting process have become compressed with the advent of word processing and other

17 The practice is not uniform. For example, scholars have documented a handful of instances of sovereign bonds issued in London under New York law, using English-law drafting conventions. See, for example, Mark Gugiatti and Anthony Richards, The Use of Collective Action Clauses in New York Law Bonds of Sovereign Borrowers, 35 Georgetown Journal of International Law 815 (Summer 2004). 
technologies, it entails substantial individual input and personal interaction, that is to say real people haggling over words. ${ }^{18}$ Once settled, core non-financial terms stay unchanged for years, as the sovereign periodically sells securities with maturities between one and thirty years under the same contract. ${ }^{19}$ On the other hand, transaction-specific terms, such as principal and interest, term structure, currency, indexation, and others that directly determine payments due under the contract, might change whenever the sovereign goes to market, while incorporating the core by reference. Normally, neither the core nor the transaction-specific terms are negotiated with individual primary market investors; however, investment bankers managing the offering are supposed to keep up with market sentiment and solicit investors' views to ensure a successful distribution. Potential future buyers of distressed bonds in the secondary market, who tend to be quite specialised and do not normally participate in primary offerings, have even fewer ways of conveying their contract preferences.

Core non-financial terms in sovereign debt contracts exhibit a remarkable degree of continuity on the one hand, with functionally similar terms and even some of the same words appearing in 19th, 20th and 21st century bonds. They exhibit an equally remarkable degree of variation among terms in contemporary contracts that purport to be functionally similar, if not identical.

A case study in variation: the pari passu clause

While there is no comprehensive study of non-financial term variation in sovereign bonds, some contract provisions have been the subject of exhaustive studies. Foremost among these is the pari passu (equal step) clause, typically found under the heading "Status," which has appeared with slight variations in sovereign bond contracts since at least the 19th century. The most prominent contemporary variations of the clause are set forth below:

\section{- $\quad$ Version 1}

The Securities are general, direct, unconditional, unsubordinated and unsecured obligations of [the sovereign] ... and [the sovereign] shall ensure that its obligations hereunder shall rank pari passu among themselves and with all of its other present and future unsecured and unsubordinated [external debt] ... (used by Belize in 2013 under New York law)

18 See, for example, Gulati and Scott, supra footnote 16.

19 For example, Kazakhstan issued ten- and thirty-year securities under its new MTN Programme in 2014, after a long period out of the market. See, for example, Moody's Investors Service, Rating Action: Moody's assigns provisional senior unsecured $(P) B a a 2$ rating to Kazakhstan's $\$ 10$ billion MTN programme (8 October 2014) (also announcing ratings for the first two eurobonds issued under the programme). 


\section{- Version 2}

[Version 1] + The payment obligations of [the sovereign] under the Securities shall at all times rank at least equally with all its other present and future unsecured and unsubordinated [external debt]. (used by Argentina in 1994 under New York law)

\section{- $\quad$ Version 3}

[Version 2] + ... save only for such obligations as may be preferred by mandatory provisions of applicable law. (used by Ukraine in 2012 under English law)

\section{- $\quad$ Version 4}

The Securities are the direct, unconditional and general and ... unsecured obligations of [the sovereign] and will rank equally with all other evidences of indebtedness issued in accordance with [this agreement] and with all other unsecured and unsubordinated general obligations of [the sovereign] for money borrowed. ... Amounts payable in respect of principal of (and interest on) the Securities will be charged upon and be payable out of the [sovereign treasury], equally and ratably with all other amounts so charged and amounts payable in respect of all other general loan obligations of [the sovereign]. (used by Italy in 2003 under New York law)

The pari passu clause in sovereign bonds has attracted tremendous market, policy and academic attention since 2000, when an Elliott Associates investment fund holding defaulted Peruvian debt got a Brussels commercial court to rule in its favour based on contract language similar to Version 2 above, which mentions "payment obligations." The court decided that Peru breached an obligation to pay its creditors equally and enjoined Euroclear from processing payments to the holders of Peru's restructured debt until Elliott was paid in full. ${ }^{20}$ Peru quickly settled and Elliott recouped several times its investment.

More than a decade later, US Federal courts in New York reached the same conclusion in a lawsuit against Argentina by a different Elliott affiliate, again using Version 2 of the clause. The courts ruled against Argentina despite interventions by the US Executive and the governments of Brazil, France and Mexico, among others, each of which insisted that the pari passu clause, including Version 2, could not be construed to require full payment to the holdouts. Argentina initially refused to settle. Court injunctions blocked the government from servicing $\$ 29$ billion of restructured debt, as well as from issuing new debt targeting foreign investors.

Leaving aside the merits of Belgian and US court decisions as a matter of law, they presented a policy conundrum. On the bright side, they paved the way to a new, potentially generalisable method of enforcing sovereign debt. A sovereign that sought to make a credible contractual commitment to repay could do so now by adopting Version 2 of the pari passu clause, construed by the courts to require rateable payment to holdouts and backed by the courts' injunctive power. Adopting

20 Elliot Assocs., L.P. v. Banco de la Nacion, General Docket No. 2000/QR/92 (Court of Appeals of Brussels, 8th Chamber, 26 September 2000). 
Version 4 of the clause, which conveys an even clearer commitment to pay, would have a similar effect. On the dark side, enforcement would come at a very high cost to the borrowing country, with potentially significant externalities. Breaching either Version 2 or Version 4 of the clause could bring about a financial boycott of the sovereign, starving the country of foreign exchange and cutting it off from trade. If the sovereign attempted to pay despite the injunction, court sanctions could disrupt systemically important payment and settlement systems, all in the name of full payment for a small minority of enterprising holdouts.

After its courts ruled in favour of the holdouts in lawsuits against Peru and Nicaragua, Belgium quickly enacted a statute shielding Euroclear from injunctions. ${ }^{21}$ Soon after, a court in London declined to interpret the pari passu clause in the Congo's debt contracts, recognising that third parties would bear the brunt of any injunctions blocking payments to sovereigns. ${ }^{22}$ Together, Belgian legislation and judicial reticence in the United Kingdom reduced the policy salience of the pari passu clause in the euromarkets. After pari passu reoccupied centre stage as a debt enforcement tool in New York in 2011, the options for managing its impact shrank dramatically. The Supreme Court effectively foreclosed the judicial path for the time being, when it refused to review lower court injunctions. Belgian-style legislation had no prospect in the United States. For those who worried about pari passu and its spillover effects on the international financial system, contract reform was all that was left.

\section{Boilerplate shock and boilerplate reform}

US federal courts in New York were under the impression that Argentina's version of the pari passu clause was unusual. Researchers found otherwise:

21 For the decision against Nicaragua, later overturned on unrelated grounds, see Republic of Nicaragua v. LNC Investments and Euroclear Bank S.A., Docket No. 240/03 (Brussels Commercial Ct. 11 September 2003). For a description of the statute, see Nationale Bank van België/Banque Nationale de Belgique, Financial Stability Review 2005, pp. 162-163.

22 "This point is, I think, closely allied to the seventh point, which concerns the nature of the relief sought generally, which is directed towards the coercion of third parties rather than securing immediate compliance by the defendant. Because I regard this last point as determinative, I regard it as unnecessary to attempt any analysis of the pari passu clause. In any event, with all respect to Cresswell J, who did not have the advantage of the observations of the amicus which have been made to me, that question would be better addressed in a debate as between the original parties to an agreement in which the clause appears and, moreover, in a case where the party seeking to enforce the clause does not derive its title in substantial part from original parties who have already colluded in its apparent breach." Kensington Int'l Ltd. v. Republic of the Congo, 2002 No. 1088, [2003] EWHC 2331 (Comm) (Commercial Ct. 16 April 2003). 
Figure 2

Pari passu clause variations

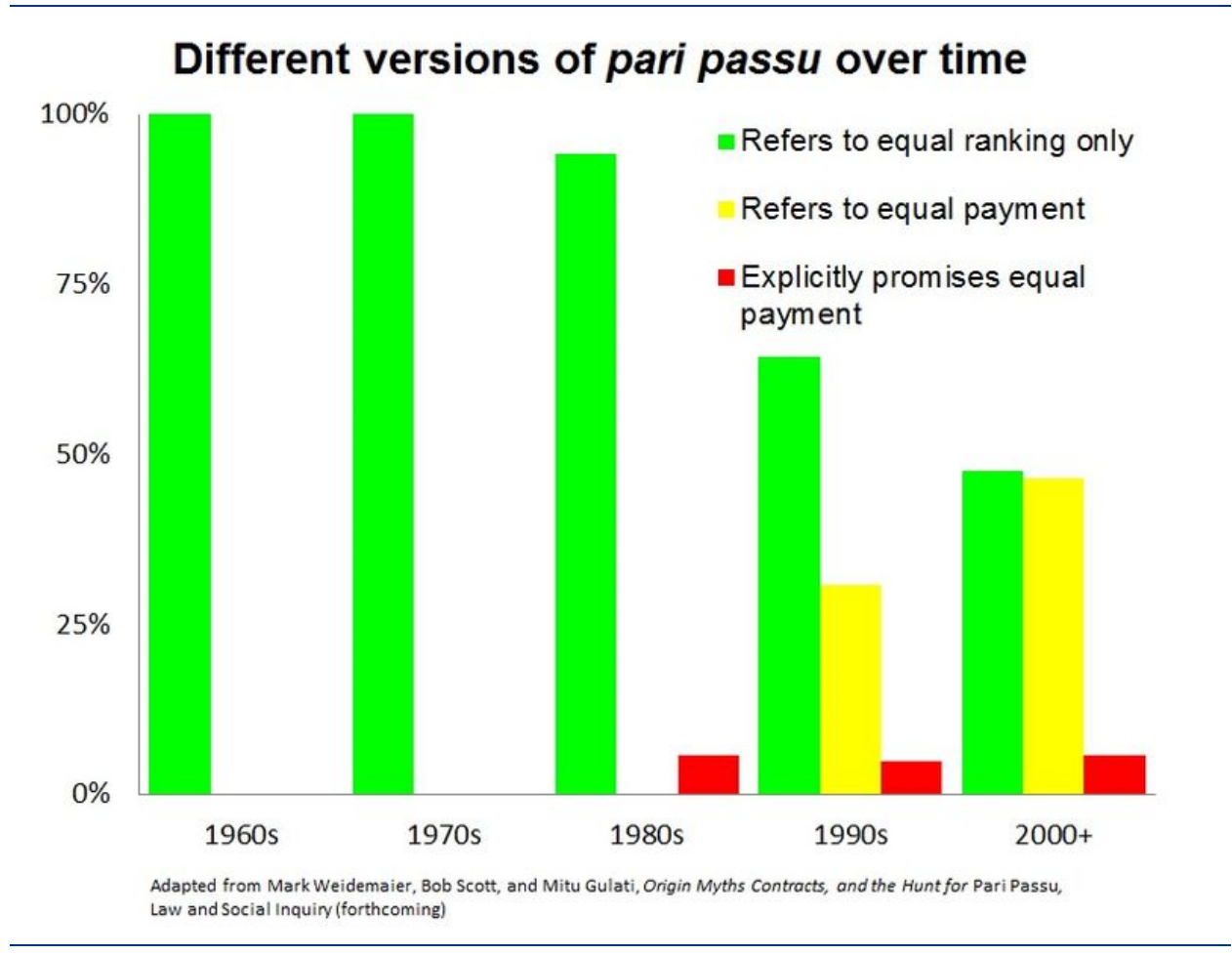

Source: Weidemaier et al. 2013

Since the revival of the foreign sovereign bond market in the 1990s, a growing number of sovereigns had chosen the "payment" version of the clause (Version 2), which made them vulnerable to injunctions in the aftermath of the Peru and Argentina rulings. The classic Version 1 of the clause, which promised equal ranking without reference to payment, seemed insulated from enforcement injunctions until another US court, responding to a copycat complaint against Grenada in 2013, left open the possibility that even a simple promise to rank pari passu might be read as supporting an injunction. ${ }^{23}$ More recently, researchers have identified a separate category of contracts (labelled Version 3 in the typology above), which on the one hand use the vulnerable "payment" wording, but also apparently allow the debtor to pass a mandatory domestic law preferring its other payment obligations. Ukraine enacted just such a law in 2015, in an attempt to neutralise its Version 3 pari passu clause. ${ }^{24}$ Finally, there was a noticeable if small contingent of Version 4 clauses, which promised rateable payment in no uncertain terms. On the whole, the growing prevalence of Version 2 clauses, along with the many variations on the pari passu theme unearthed in the wake of recent lawsuits, has sown confusion about the nature and effect of standardisation in sovereign bond contracts and the precise nature and scope of the threat to the system from pari passu.

23 The court refused to dismiss the case and ordered it to proceed to trial on the assumption (albeit for the sake of argument) that Grenada's Version 1 clause was "similar" to Argentina's Version 2 clause, see Export-Import Bank of the Republic of China v. Grenada, Opinion and Order, 13 Civ. 1350 (HB) (SDNY) (19 August 2013), p. 5, see http://www.creditslips.org/files/grenada.districtcourtdecision081913.pdf. The case was settled without a definitive ruling on the meaning of Grenada's Version 1 clause.

24 No court has construed a Version 3 clause to date. 
Beginning in 2012, an informal working group ${ }^{25}$ of policy officials, debt managers, market participants, lawyers and academics considered options for revising the pari passu clause, as well as majority modification CACs, in foreign sovereign bonds. ${ }^{26}$ The group's work culminated in the release of new model clauses by the International Capital Market Association (ICMA), endorsed by the Group of 20 and the IMF. ${ }^{27}$ The new pari passu clause reads as follows:

\section{- $\quad$ Version 5 (ICMA Clause)}

The Notes are the direct, unconditional and unsecured obligations of the Issuer and rank and will rank pari passu, without preference among themselves, with all other unsecured External Indebtedness of the Issuer, from time to time outstanding, provided, however, that the Issuer shall have no obligation to effect equal or rateable payment(s) at any time with respect to any such other External Indebtedness and, in particular, shall have no obligation to pay other External Indebtedness at the same time or as a condition of paying sums due on the Notes and vice versa.

The new model clause, which reflected several rounds of consultation with market participants, combined the simple ranking formulation of the old pari passu clause (Version 1) with an express disavowal of the rateable payment interpretation that had supported injunctions against Argentina and Peru. The disavowal stripped pari passu of its recently-acquired powers; however, the range of sovereign misdeeds it proscribed was vanishingly narrow, most likely limited to domestic laws subordinating the creditors. ${ }^{28}$

The reformulated pari passu clause was incorporated in ICMA's Primary Market Handbook, a guidance document addressed to its membership, which includes most major financial market participants, including issuers, buy-side and sell-side investors. Although members are expected to follow the guidance, it is a relatively soft coordination device: the model clause language is seen as a public good; it is neither strictly mandatory, nor rigorously policed. ${ }^{29}$ The IMF similarly does not mandate the inclusion of particular language in its sovereign members' contracts; it

25 The author of this essay participated in the working group.

26 See, for example, Mark Sobel, Strengthening collective action clauses: catalysing change-the back story, Capital Markets Law Journal (2016) 11 (1): 3-11 first published online January 11, 2016, and Anna Gelpern, Ben Heller and Brad Setser, "Count the Limbs: Designing Robust Aggregation Clauses in Sovereign Bonds" in Martin Guzman, Jose Antonio Ocampo and Joseph E. Stiglitz, Too Little, Too Late: The Quest to Resolve Sovereign Debt Crises (Initiative for Policy Dialogue at Columbia 2016).

27 See, for example, Sobel, supra footnote 26.

28 The argument for the narrow reading is articulated in, for example, Lee C. Buchheit and Jeremiah S. Pam, The Pari Passu Clause in Sovereign Debt Instruments, 53 Emory Law Journal 870 (2004) and Phillip Wood, Pari Passu Clauses - What do they Mean? 18 Butterworths Journal of International Banking and Financial Law 371 (2003)

29 Compare Davis, supra footnote 4. The handbook is available at: http://www.icmagroup.org/Regulatory Policy-and-Market-Practice/Primary-Markets/ipma-handbook-home/ 
merely recommends the inclusion of terms (such as ICMA clauses) that would have the desired policy effect. ${ }^{30}$

Nonetheless, the entire coordination effort that brought about Version 5 of the pari passu clause was premised on a high degree of contract standardisation. The goals of reducing uncertainty and containing the spillover effects of pari passu as an enforcement tool would hardly be advanced if sovereigns and their creditors all varied significantly from the model clause, leaving future courts to sort out the mix of common standard and idiosyncratic meaning they sought to convey. Yet variation is precisely what happened immediately following the release of ICMA's version of pari passu in August 2014. The examples below illustrate:

- $\quad$ Ghana (September 2014, English law)

The Notes constitute direct, unconditional and ... unsecured obligations of the Issuer and ... rank and will rank pari passu, without any preference among themselves and with all other present and future unsecured and unsubordinated obligations of the Issuer, save only for such obligations as may be preferred by mandatory provisions of applicable law, provided, however, that the Issuer shall have no obligation to effect equal or rateable payment(s) at any time with respect to any such other unsecured and unsubordinated obligations of the Issuer and, in particular, shall have no obligation to pay other unsecured and unsubordinated obligations of the Issuer at the same time or as a condition of paying sums due on the Notes and vice versa.

- $\quad$ Kazakhstan (November 2014, English law)

The Notes will at all times rank pari passu without preference among themselves and at least pari passu in right of payment, with all other unsecured External Indebtedness of the Issuer from time to time outstanding, provided, however, that the Issuer shall have no obligation to effect equal or rateable payment(s) at any time with respect to the Notes or any other External Indebtedness and, in particular, shall have no obligation to pay other External Indebtedness at the same time or as a condition of paying sums due on the Notes and vice versa.

- $\quad$ Vietnam (November 2014, New York law)

The Notes shall at all times rank without any preference among themselves and equally with all other present and future unsecured and unsubordinated External Indebtedness ... provided, however, consistent with similar provisions in the Government's other External Indebtedness, that this provision shall not be construed so as to oblige the Government to effect equal or rateable payment(s) at any time with respect to any such other External Indebtedness and, in particular, it shall not be construed so as to

30 See, for example, IMF, Strengthening the Contractual Framework to Address Collective Action Problems in Sovereign Debt Restructuring (Staff Report and Press Release, October 2014) available at: http://www.imf.org/external/np/pp/eng/2014/090214.pdf, and Chanda DeLong and Nikita Aggarwal, Strengthening the contractual framework for sovereign debt restructuring-the IMF's perspective, Capital Markets Law Journal (2016) 11 (1): 25-37 first published online January 11, 2016. 
oblige the Government to pay other External Indebtedness at the same time or as a condition of paying sums due on the Notes and vice versa.

- $\quad$ Mexico (November 2014, New York law)

The debt securities rank and will rank without any preference among themselves and equally with all other unsubordinated public external indebtedness of Mexico. It is understood that this provision shall not be construed so as to require Mexico to make payments under the debt securities ratably with payments being made under any other public external indebtedness.

Each of the above "early adopter" clauses includes the central innovation of ICMA's model, the disavowal of rateable payment; each might be sensibly classified as a "Version 5" clause. However, Ghana combines the Version 5 disavowal with additional flexibility to enact domestic laws subordinating the bondholders, also in Version 3. Kazakhstan's Version 5 incorporates a reference to payment, echoing Version 2, which had prompted the latest contract reform effort. Vietnam's and Mexico's clause replaces the Latin "pari passu" with the English term "equally," and appears to address the disavowal of rateable payment to the courts ("shall not be construed"). Vietnam moreover tries to extend the disavowal to its outstanding debt, which did not explicitly reject the rateable payment meaning.

What to make of this variation? It is easy enough to find an explanation for each of the early adopter clauses: some lawyers combined ICMA's model with their clients' old boilerplate; others sought to reconcile the language drafted by ICMA's English lawyers with local market conventions, in effect proposing a distinct-but-consistent New York standard. ${ }^{31}$ Some or all might have thought that their phrasing was more elegant, or did a better job of protecting their clients on the margins. In public, everyone claimed that their clause followed ICMA recommendations endorsed by the IMF and that any variation from the model was non-substantive. This was quite unsettling in the wake of recent sovereign debt lawsuits, which showed, if anything, that variation as such posed a risk. Reigning in variation that turned out to be problematic ex post was an important objective for the public-private collaboration that yielded ICMA's model pari passu clause.

Even if one found ICMA's model clunky, or worse, internally inconsistent for promising equal treatment except when it really mattered, the model had the advantage of industry and public sector backing, along with well-publicised, accessible drafter's intent. ${ }^{32}$ Years from now, a court construing early variations on ICMA's model pari passu clause would be hard-pressed to conclude that any of them were non-substantive, a product of mindless copying. ${ }^{33}$ After all, these had to be among the most carefully considered pari passu clauses of all time. Pari passu had

31 ICMA formally introduced the New York model in May 2015. See http://www.icmagroup.org/resources/Sovereign-Debt-Information/

32 See, for example, Stephen J. Choi and G. Mitu Gulati, Contract as Statute 104 Michigan Law Review 1129 (2006) (addressing the problem of discerning the parties' intent in boilerplate terms) and Davis, supra footnote 4

33 See, for example, Gugiatti and Richards, supra footnote 17. 
been the focus of policy and market attention for three years leading up to their production. The lawyers, bankers and officials responsible for contract design either participated in working group efforts directly, engaged in consultations or were targeted in outreach efforts early on. As a result, a future court might well conclude that any early adopter who chose to depart from the model did so deliberately, to achieve an objective distinct from that of the model. If this were not the result debtors and creditors had intended, perhaps their lawyers did not do their jobs: variation might indicate a persistent agency problem. ${ }^{34}$ An investor mindful of this prospect would see a wealth of arbitrage opportunities.

Another challenge arises from the way in which contracts are revised. Sovereigns typically do not update their outstanding contracts and only incorporate innovations in new issue documentation. IMF staff estimated that, when the ICMA released the latest model pari passu clause, the stock of foreign sovereign bonds outstanding was approximately $\$ 900$ billion, of which $71 \%$ would mature within a decade. ${ }^{35}$ Even if all new bonds adopted ICMA model clauses, it would take over a decade for the entire stock to transition to the new standard. Until then, reformed and unreformed contracts, each "standard" for its time, would trade in parallel. If bond market participants viewed the old bond contracts as structurally senior or subordinate to the new, the result would be a fragmented, stratified debt stock vulnerable to opportunistic intervention.

\section{Whither sovereign debt contracts?}

The pari passu episode, which began with a Belgian court ruling against Peru and ended (for now) with the introduction of ICMA clauses, highlighted several features of contracting in the foreign sovereign debt market. First, the market has at least two distinct and widely used standards - English law and New York law - which claim to achieve the same goals with different combinations of words.

Second, each of the two standards permits a degree of variation, including borrowing from one another, which the drafters (rightly or wrongly) describe as non-substantive. Apparently routine departures from the standard are almost never tested in court; when they are, some pose a real risk of divergent interpretation and market disruption. The risk of disruption is highest when there is no compelling evidence of market usage to give a contract term contemporary meaning. ${ }^{36}$ Doctrinally, it must mean something - in practice, it could mean anything. The "payment" version of the pari passu clause used by Peru and Argentina, which eminent lawyers had described as functionally equivalent to the "ranking" version, is a case in point.

The third feature of sovereign debt contracting is its apparent susceptibility to coordination by public and private actors. The production of ICMA model thirdgeneration CACs and pari passu clauses in 2014 and 2015 is only the latest

\footnotetext{
34 See, for example, Gulati and Scott, supra footnote 16.

35 IMF, supra footnote 29, p. 33.

36 See, for example, Choi, Gulati and Scott, supra footnote 3.
} 
example of such coordination. From 2010 to 2013, European debt officials managed the adoption of second-generation CACs in euro area government bonds, implementing their governments' commitment in the Treaty establishing the European Stability Mechanism. ${ }^{37}$ That initiative was styled as a successor to an earlier drafting effort under the auspices of the Group of Ten from 2002 to 2003, which led to the adoption of first-generation CACs in New York-law bonds issued by emerging market governments, as well as in European foreign sovereign bonds and the first recommendation concerning CACs in the ICMA handbook. ${ }^{38}$ ICMA's predecessors in the London market, along with a handful of industry groups in New York and Washington, engaged with the official sector for almost a decade leading up to the 2003 reform. In the early 1990s, bankers and officials worked closely together to design the Brady Bonds, which became the preferred vehicle for restructuring sovereign debt to banks. The Emerging Market Traders Association (EMTA) almost immediately began producing market practice and trading documentation for these bonds, helping to spur a sovereign bond market revival after half a century of inactivity. ${ }^{39}$ The experience of the League of Nations Committee for the Study of International Loan Contracts in the 1930s, responding to an earlier wave of sovereign defaults, suggests that the roots of coordination and public-private collaboration in sovereign debt contracting run extremely deep, even if the results fall short of the stated objectives. ${ }^{40}$

\section{Room for improvement}

Fallout from the latest pari passu episode suggests that the sovereign debt market could benefit from more robust contract standardisation. Pervasive minor variations make it hard for market participants and the courts to distinguish between lawyerly noise and deliberate customisation. Investors tempted to consider bond contracts solely through the prism of a yes/no covenant checklist might end up with treasure or unexploded ordnance in their vaults. ${ }^{41}$

Debtors and their investment bankers are reluctant to change bond contracts to improve crisis management, which most describe as a remote contingency, for fear of sending a negative signal and raising their cost of borrowing. On the rare

37 See, for example, the following documents available at: http://europa.eu/rapid/press-release_DOC-123_en.htm and http://europa.eu/efc/collective-action-clauses-euro-area_en

38 See, for example, the following documents available at: http://europa.eu/efc/collective-action-clauseseuro-area_en and http://www.icmagroup.org/Regulatory-Policy-and-Market-Practice/PrimaryMarkets/primary-market-topics/collective-action-clauses/

39 See, for example: http://www.emta.org/template.aspx?id=58

40 The committee was active between 1935 and 1939. It mobilised experts from the financial industry, lawyers, academics, and government officials, and produced a report recommending changes in sovereign debt documentation and practice. League of Nations Report of the Committee for the Study of International Loan Contracts, Geneva (1939).

41 Knowing that a bond has a pari passu clause or a CAC is close to meaningless without knowing what kind of pari passu clause and what kind of CAC it contains. 
occasions when contracts do change, the large stock of legacy bonds detracts from the benefits of innovation and creates opportunities for abuse. Paradoxically, policy interventions to reform sovereign bond contracts to limit the cost of financial crises appear to be premised on a far greater degree of standardisation than that which prevails in the market. In some cases, reform initiatives open the gates of innovation only to amplify the range of variation. ${ }^{42}$

Two broad approaches have been proposed to deal with aspects of this problem in relation to sovereign debt. The first is a sovereign bankruptcy treaty, which would override a subset of sovereign bond contract terms in a crisis, and facilitate a restructuring. The treaty would have to reflect a global consensus on topics such as the meaning of equal treatment, and chart an intelligible a roadmap for restructuring..$^{43}$ It could be drafted to apply to the old contracts and deal with the problem of outstanding stock. At the other extreme, scholars have recently proposed giving judges the ability to declare a standard term meaningless when presented with compelling evidence that it has lost content from decades of rote repetition and random, acontextual variation. ${ }^{44}$ This approach could also address the outstanding stock problem, albeit in a more limited, ad hoc fashion.

A third possibility might combine contract, statute and interpretation in a single institutional mechanism. The derivatives industry offers an example.

The global over-the-counter (OTC) derivatives market is organised around a common contract produced and copyrighted by the International Swaps and Derivatives Association (ISDA), which underpins transactions referencing close to $\$ 500$ trillion in notional amounts outstanding. ${ }^{45}$ The ISDA master agreement functions as the hub for contract modules that, together with the master agreement, make up a derivatives contract. These include relationship-specific schedules and annexes negotiated among market participants. Product-specific sets of definitions correspond to particular types of transactions, such as interest rate, equity, or credit default swaps. Transaction-specific confirmations contain the relevant financial terms and incorporate the master agreement, the schedules and any other relevant parts of the contract apparatus by reference. In the example depicted in Figure 3, the darklyshaded modules are transaction-specific, the medium-shaded module is relationshipspecific and the unshaded modules are standardised. The entire structure, comprising all transactions across a bilateral relationship, constitutes a single

42 See, for example, Anna Gelpern and Mitu Gulati, Innovation after the Revolution: Foreign Sovereign Bond Contracts Since 2003, Capital Markets Law Journal 4 (no. 1): 85-103.

43 For a recent overview of the debate, see, for example, 41 Yale Journal of International Law, Special Edition on Sovereign Debt (2016).

44 Choi, Gulati and Scott, supra footnote 3.

45 Notional amounts outstanding. The Bank for International Settlements OTC derivatives statistics up to the first half of 2016 are available at: www.bis.org/statistics/derstats.htm (Table D5). 
contract, enabling the counterparties to manage the relationship on a portfolio basis. $^{46}$

Figure 3

Derivatives contract architecture - an illustration

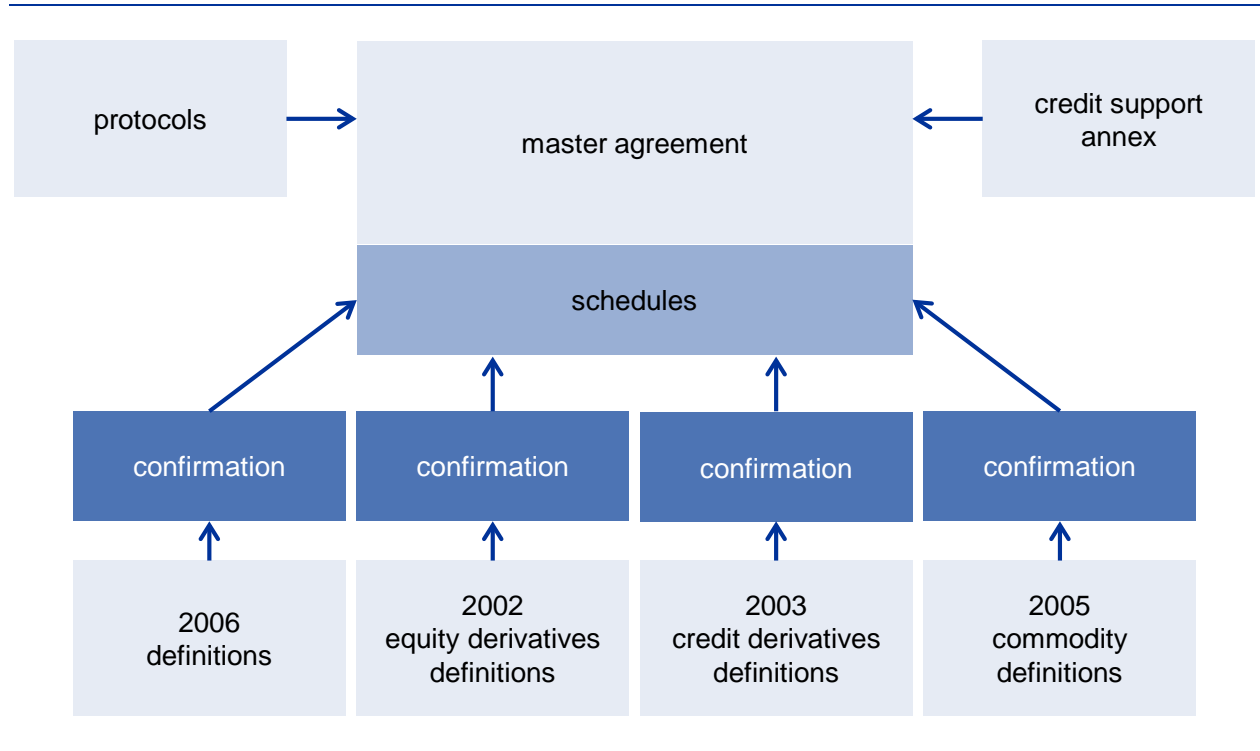

Robust standardisation need not mean enforced uniformity. In Figure 3, the parties are free to customise, so long as they do so in designated places - schedules and confirmations - which makes departures from the standard easier to spot and to analyse (and, as many commentators have noted, creates a barrier to variation). This structure also offers a partial solution to the outstanding stock problem in contract reform. The ISDA protocol process, first used in 1998 in as part of the transition to European economic and monetary union, gives members the option of acceding to a common document (a protocol) amending the master agreement. ISDA posts the protocol on its website and keeps a tally of adherents. Once two members have agreed to adhere to a common protocol, they have effectively amended their bilateral contracts to reflect the new terms. ${ }^{47}$ Protocols reduce the need for bilateral negotiations, while reassuring market participants that the amendment in fact reflects industry preference. The solution to the stock problem is only partial, however, since when a new generation master agreement comes out, transactions governed by the old master agreement do not move to the new standard.

ISDA started out as a dealers' group in the 1980s, responding to demand for a common "vocabulary" in the transatlantic derivatives market. Although it is still

46 For an accessible overview of the ISDA contract architecture, see GuyLaine Charles, The ISDA Master Agreement, Part I: Architecture, Risk, and Compliance, Practical Compliance and Risk Management for the Securities Industry (January-February 2012) and GuyLaine Charles, The ISDA Master Agreement, Part II: Negotiated Provisions, Practical Compliance and Risk Management for the Securities Industry (May-June 2012).

47 ISDA's description of the protocol process, "About ISDA Protocols" is available at: http://www2.isda.org/functional-areas/protocol-management/about-isda-protocols/ 
dominated by large financial institutions, the group has expanded its membership over time to include smaller funds, non-financial companies that use derivatives for risk management, and service providers. It has also sought to ensure that its contracts are enforceable around the world. ISDA's contracts are drafted by outside lawyers and in-house staff, working under the auspices of ISDA's documentation committee. The committee has thousands of members, although only a small subset participate actively. The same actors decide when a new master agreement or a new set of definitions might be needed to address a new product, responding to regulatory or market developments.

Since its inception, ISDA's work has expanded beyond contract drafting, to other areas of market practice, infrastructure, contract interpretation and private adjudication. Owing to the transnational reach of its contracts, their widespread adoption and high degree of standardisation, ISDA has become an indispensable intermediary between market participants, governments and international regulatory fora, projecting quasi-statutory power across its market. For example, in 2012, it worked with policy makers to minimise market disruption from the Greek debt restructuring, ${ }^{48}$ while in 2014 and 2015, it published protocols to facilitate marketwide recognition of national laws for resolving large cross-border financial institutions, the result of intense collaboration with the Financial Stability Board (FSB) and regulators in major financial jurisdictions. ${ }^{49}$

ISDA may be the best known instance of centralised, modular contracting in the financial industry, but it is not unique. For example, the foreign exchange market, with its daily turnover exceeding $\$ 5$ trillion, ${ }^{50}$ also uses a structure comprising standard-form master agreements, schedules, definitions and procedures, for foreign exchange and currency options transactions. The contracts are drafted by financial industry lawyers working with major foreign exchange market participants. In the United States, the drafters are part of the Financial Market Lawyers Group, sponsored by the Federal Reserve Bank of New York. The financial firms are represented by regional trade associations. ${ }^{51}$ Like the push to standardise derivatives documentation, centralised production of standard-form foreign exchange contracts began in the 1980s; in both cases, standardisation gets much credit for the explosive market growth.

More distant analogues go back to the interwar period in the first half of the $20^{\text {th }}$ century, and include initiatives such as the Uniform Customs and Practice for Documentary Credit (UCP) in trade finance that grew out of international banks'

48 See, for example, Anna Gelpern and Mitu Gulati, CDS Zombies, 13 European Business Organisations Law Review 347 (2012).

49 See, for example, David Geen, Seth Grosshandler, Katherine Hughes, Igor Kleyman, Knox L. Mcllwain, Samantha Riley, and M. Benjamin Snodgrass, A Step Closer to Ending Too-Big-to-Fail: The ISDA 2014 Resolution Stay Protocol and Contractual Recognition of Cross-border Resolution, 35 Journal on the Law of Investment and Risk Management Products 35:3 (April 2015), and http://www2. isda.org/functional-areas/protocol-management/protocol/22. The protocols are available at ISDA, supra footnote 46.

50 BIS Triennial Central Bank Survey: Foreign exchange turnover in April 2016 (September 2016, updated December 11, 2016) available at: http://www.bis.org/publ/rpfx16fx.pdf

51 Financial Markets Lawyers Group, Documentation: FXC Master Agreements, available at: https://www.newyorkfed.org/fmlg/documentation/master.html 
attempt to coordinate their practices with respect to documentary letters of credit. UCP is produced under the auspices of the International Chamber of Commerce (ICC) Banking Commission, which now also publishes practice documents in other areas of trade finance, oversees their revision and issues authoritative interpretations. $^{52}$

In all these examples, financial industry members came together to produce a set of contract terms, which were then adopted wholesale, with limited variation, across the target market. The industry body took responsibility for the ongoing revision of standard terms and, increasingly, for their interpretation, which has elicited deference from the courts. ${ }^{53}$ Over time, the industry body engaged in repeated instances of collaboration with governments and international organisations. Standard-form contracts became the basis for more elaborate interweaving and institutionalisation of policy and market practice even in the absence of treaties or statutes. The next part considers whether such a model might be suitable for the foreign sovereign debt market.

Who is afraid of sovereign boilerplate?

It would not take much to map ISDA's modular contract design illustrated in Figure 3 onto the existing foreign sovereign bond contract structure in Figure 1. An industry body such as ICMA, perhaps in collaboration with a public institution such as the IMF or the FSB, and a rotating complement of sovereign debt managers and their lawyers, could draft the core non-financial terms of a New York trust indenture or English trust deed, including representations, covenants and events of default. The standard form might offer a menu of options for some terms, and make other terms optional. The draft would be released for a period of public consultation, including market and civil society outreach, on the administrative law model. At the conclusion of the consultation process, the result would be posted on a dedicated website along with any public comments received as part of the process. Sovereign borrowers would then incorporate the resulting terms by reference in future transactions, with customised terms confined to separate schedules.

The drafting group would meet regularly, say, twice a year, to consider recent developments and the potential need to revise or augment the standard form. Additional extraordinary meetings might be called in response to events that require prompt contract adaptation. Proposed revisions would be issued in a protocol, so that they might operate retroactively among any debtors and creditors who agreed to adhere to them. To minimise the legacy stock problem and the associated free-riding opportunities, the initial agreement could stipulate that protocols winning the

\footnotetext{
52 See, for example, Janet Koven Levit, A Bottom-Up Approach to International Lawmaking: The Tale of Three Trade Finance Instruments, 30 Yale Journal of International Law 125 (2005). UCP underwent its sixth revision (UCP 600) in 2007. For the text of UCP 600 and the current range of ICC Banking Commission activities, see the commission website, at http://www.iccwbo.org/advocacy-codes-andrules/areas-of-work/commission-on-banking/

53 Levit, supra footnote 52.
} 
adherence of a specified majority of outstanding bond holders affected by the proposed revision would bind all the remaining holders as well.

Such an approach to sovereign bond contracting would help ensure that standard portions of the contract are in fact standard and vetted by the relevant stakeholders, adding an element of public accountability that is mostly missing today. It would expressly acknowledge variations within the standard and highlight deviations from the standard. It would also facilitate ongoing collective revision of the terms, although it would also dampen individual initiative. To counter the tendency to boilerplate ossification and encourage culling, the drafting group could get standing authority to initiate revisions following regular reviews. Over time, the group may issue authoritative interpretations of its standard terms and articulate best practices with respect to disclosure, debtor-creditor engagement, and other process matters. ${ }^{54}$

What is not to like in such an approach?

Although the centralised and modular contract production could have important advantages over the status quo, it would also pose new challenges. First, there is the matter of constituting the drafting group. It is implausible and undesirable for sovereign borrowers simply to delegate their debt contracts to a private industry body comprising large financial firms, or even to other governments. On the other hand, a drafting committee comprising all sovereign governments borrowing in the international markets under foreign law would be unwieldy. Rotating the membership in a way that ensures balanced representation from different regions and income groups may be acceptable to most sovereigns, but political sensitivities would remain.

Market participants would face representation challenges of their own: most existing industry bodies tend to skew in favour of the largest financial firms, which have more bargaining power and greater capacity to dedicate personnel to industry business. Distressed debt investors and others who normally eschew primary offerings, have no direct input in contract terms for the time being; market participants disagree on the extent to which secondary market prices convey such investors' views regarding contract terms. In the new drafting process, funds known for aggressive enforcement tactics would probably insist on being included; however, their contract preferences might well differ from those of the larger and more passive investors, who dominate primary markets today.

Second and related, decision-making rules would represent another hurdle: anything other than consensus would be controversial, but consensus might be unachievable. For example, the existence of a newly robust standard form contract, and the resulting presumption that any deviation from it is meaningful, could make deviation more costly. Countries that fear penalties for deviation might block agreement on a standard they dislike, raising the barrier to innovation higher for everyone.

54 The existing Principles for Stable Capital Flows and Debt Restructuring, initiated by the Institute of International Finance (IIF), the Principles for Sovereign Lending and Borrowing and Sovereign Restructuring issued by the United Nations Conference on Trade and Development (UNCTAD), the UN General Assembly resolutions on sovereign debt restructuring, as well as ICMA's latest disclosure requirements promulgated as part of the model CACs, could all be harnessed as part of this effort. 
Third, the new contracts would have to account for existing and future market segmentation. For example, it is generally understood, though rarely acknowledged in public, that sovereigns with different credit ratings may have different foreign bond contracts. At the moment, much of this segmentation in contract drafting is relatively subtle and easy to hide in the din of apparently random variation. This also makes it easier for countries to change their contracts below the radar screen as they move up and down the credit ladder. A centralised drafting effort might produce different standards for different market segments, for example, by geographic region, credit quality, currency, or governing law, effectively forcing countries to classify themselves, a politically fraught outcome. It could also choose to issue a single standard and leave market segmentation to the schedules, where differences attributable to hierarchical factors could be muted more easily. An overly large menu of standards, or a single standard contemplating substantial variation in the schedules, would detract from the goal of robust standardisation, although neither is likely to be fatal to the overall effort.

Fourth, there is the matter of getting sovereign governments to follow through on their commitments to standardise. No one can force a country to adopt a particular contract term or contracting process, a challenge evident in the IMF's soft-touch approach to endorsing ICMA clauses and its predecessors. However, to the extent that new, centrally-produced terms would be accepted as the market standard, sovereigns might come under pressure from their investors to adopt such terms. Clearing and payment systems might also make access conditional on the adoption of the terms. Favourable treatment of centrally-produced contracts under bank, insurance, asset management and pension fund regulations would make them more liquid, creating additional adoption incentives.

Fifth, an attempt to centralise contract production could face opposition from the lawyers and bankers who currently produce sovereign bond contracts and are rather protective of their creative output. Even if such objections all amounted to rentseeking, they would be hard to ignore, especially since the new regime would want to harness these actors' expertise and documentation archives. On the bright side, lawyers active in the sovereign debt market are a relatively small community, comprising a few dozen lawyers, mostly within large firms. It is quite possible that all or most would find a role in negotiating relationship- and transaction-specific terms for existing clients and also participate in the group drafting effort.

Finally, it is quite possible that the current, very incomplete standardisation in fact reflects the preferences of sovereign borrowers and their creditors. Most sovereigns issuing bonds abroad under foreign law may well prefer a world where contracts are ambiguous and noisy, even though they harbour latent risks of the sort that materialised in the case of Argentina. Modern-day reform initiatives to introduce CACs and change the pari passu clause tried hard to mute any signal from contract change. On the other hand, the average investor may prefer to trade contracts that are "standard enough," so that in most cases, careful analysis of the terms does not pay off. The small minority investing based on a thorough reading of the contract may be only too happy to keep the arbitrage opportunity to itself. 
The foregoing objections are illustrative. The broad concern is that, in exchange for greater standardisation and more "statute-like" contracts, the sovereign debt market would find itself struggling with new and thorny political economy challenges. Centralised contract production would reallocate transactional and governance resources; it would empower some actors and constrain others. It is hard to tell in the abstract whether the trade-off would be an improvement on balance. That judgment would depend on specific institutional features of the new regime, and the resulting balance between stability and innovation, broad-based representation and individual initiative, among others.

\section{Conclusions}

Recent litigation and contract reform initiatives in the foreign sovereign debt market highlight the risks of haphazard, incomplete standardisation. While deliberate variation in contract terms can convey information, save borrowing costs and improve the parties' capacity to deal with contingencies, it is far from certain that existing variation is either deliberate or optimal.

Further research into the nature and extent of variation in sovereign bond terms beyond CACs and the pari passu clause would help diagnose the extent of the problem. It would also help identify how many distinct, more-or-less internally coherent documentation standards exist in the foreign sovereign debt market, so that parties' claims that their contracts are standard for one market segment and functionally equivalent to another, could be verified. Ascertaining the market standard or standards should inform the decision to proceed with more robust standardisation.

Pending further research, it makes sense to take sovereign borrowers and their creditors at their word: if robust standardisation is an important contracting objective, the sovereign bond market can get much closer to it with just a few relatively modest steps. Harnessing existing coordination mechanisms and contracting practices in the market, sovereigns and other stakeholders could, at a minimum, produce a standard set of core non-financial terms to be incorporated by reference in their transactions. Governance would present the biggest obstacle to standardisation on this model. Nonetheless, the centralised, modular contract alternative is worth a try given the risks embedded in the current regime and the difficulty of implementing statutory solutions. If debtors and creditors reject it, maybe they do not want to be standard after all. 


\section{ESCB Legal Conference 2016}

6-7 October 2016

\section{January 2017}




\section{Contents}

\section{Chapter I - Legal issues on government debt restructuring}

Reflections on the feasibility of a sovereign debt restructuring mechanism in the euro area

By Yves Mersch

Sovereign debt restructuring in the IMF experience

By Ross Leckow and Julianne Ams

The importance of being standard

By Anna Gelpern

The Greek debt restructuring of 2012

By Lee C. Buchheit

A view from Greece: the need to restructure Greece's debt

By Georgios Kyrtsos

How to fill the international law lacunae in sovereign insolvency in European Union law?

By Rosa María Lastra

How could the general principles of national insolvency law contribute to the development of a state insolvency regime?

By Christoph G. Paulus

Debt restructuring in the light of Pringle and Gauweiler - flexibility and conditionality

By Michael Ioannidis

Issues and possible reforms in the context of a euro area/EU sovereign insolvency framework

By Otto Heinz

A sovereign debt restructuring mechanism for the euro area? No bail-out and the monetary financing prohibition

By Heribert Hirte

\section{Chapter II - Legal developments in the ESCB central banking functions}

Legal analysis in a changing environment

By Yves Mersch

Technological innovations and the future of payments

By Chiara Zilioli 
Distributed ledger technologies in financial markets?: An introduction and some points of interest for legal analysis

By Andrea Pinna

Virtual currencies: the regulatory challenges

By Ross Leckow

Retail instant payments and digital innovation - an overview of risks and challenges

By Phoebus Athanassiou

Collateral issues

Introduction

By Otto Heinz

Legal shortcomings of financial market integration in the context of collateral taking: a market infrastructure perspective

By Markus Mayers

Collateral: need for legislative changes?

By Kestutis Laurinavicius

Central banks' relations with auditors (scope of control/audit gap/accountability)

Introduction

By Christian Kroppenstedt

The external audit of the ECB - an analysis of Article 27 of the Statute of the ESCB

By David Baez Seara and Simona Lambrinoc-Schanz

The impact of the establishment of the SSM on the relationship between De Nederlandsche Bank and the Netherlands Court of Audit By Willem Bovenschen

Unified administrative law at the European level

Introduction

By Eleni Koupepidou

The SSM Framework Regulation as a source of ECB administrative procedural law

By Klaus Lackhoff

Primary law requirements for administrative procedures in the case-law of the Court of Justice

By Karl-Philipp Wojcik 
Managing administrative complexity in resolution: the recent experience in Italy and its lessons from a European Union perspective By Monica Marcucci

Experience gained in the application of national law at European level

Introduction

By Niall J. Lenihan

When does national law transpose a directive?

By Andreas Witte

Level playing field: towards a more uniform application of banking legislation

By Lucía Arranz

The application of national law by the ECB - a maze of (un)answered questions

By Alexander Kornezov

Procurement law and central banking

Introduction

By Mikael S. Stenström

The principles of ECB procurement rules, with a special focus on cooperation agreements

By Isabell Koepfer

EPCO - Coordinating joint procurements in the Eurosystem/ESCB

By Tamás Csepely-Knorr

The interaction between European Union, ECB and national laws in the context of procuring euro banknotes

By Torsten Schäfer

The EU and EMU as correlated institutions beyond the State - Keynote speech

By Jaap Hoeksma

Concluding remarks

By Chiara Zilioli 